\title{
The Current State of the Arbitrage Pricing Theory
}

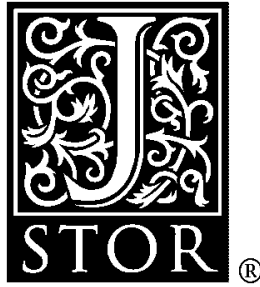

\author{
Jay Shanken
}

The Journal of Finance, Vol. 47, No. 4. (Sep., 1992), pp. 1569-1574.

Stable URL:

http://links.jstor.org/sici?sici=0022-1082\%28199209\%2947\%3A4\%3C1569\%3ATCSOTA\%3E2.0.CO\%3B2-S

The Journal of Finance is currently published by American Finance Association.

Your use of the JSTOR archive indicates your acceptance of JSTOR's Terms and Conditions of Use, available at

http://www.jstor.org/about/terms.html. JSTOR's Terms and Conditions of Use provides, in part, that unless you have obtained prior permission, you may not download an entire issue of a journal or multiple copies of articles, and you may use content in the JSTOR archive only for your personal, non-commercial use.

Please contact the publisher regarding any further use of this work. Publisher contact information may be obtained at http://www.jstor.org/journals/afina.html.

Each copy of any part of a JSTOR transmission must contain the same copyright notice that appears on the screen or printed page of such transmission.

The JSTOR Archive is a trusted digital repository providing for long-term preservation and access to leading academic journals and scholarly literature from around the world. The Archive is supported by libraries, scholarly societies, publishers, and foundations. It is an initiative of JSTOR, a not-for-profit organization with a mission to help the scholarly community take advantage of advances in technology. For more information regarding JSTOR, please contact support@ jstor.org. 


\title{
The Current State of the Arbitrage Pricing Theory
}

\author{
JAY SHANKEN*
}

\begin{abstract}
This paper provides a simple proof of a recent theorem presented by Reisman (1992), concerning the use of proxies for the factors in the return-generating process of the arbitrage pricing theory (APT). In the single-factor case, the theorem asserts that any variable correlated with the factor can serve as the benchmark in an approximate APT expected return relation. The significance of this result is considered and a new direction for empirical work on "arbitrage pricing" is outlined.
\end{abstract}

GIVEN A FACTOR MODEL for an infinite sequence of asset returns, Ross (1976) showed that the absence of arbitrage implies an approximate linear relation between expected returns and the factor betas. ${ }^{1}$ Ross assumed that returns conform to a strict factor structure, i.e., a factor model with uncorrelated disturbances, but noted that this condition could be weakened in deriving the arbitrage pricing theory (APT). Nonetheless, statistical methods based on the strict factor model assumption dominated the early empirical work on the APT.

At first glance, the requirement of a strict factor structure appeared to impose a strong restriction on the sets of factors that could be used as a benchmark for measuring systematic risk. Shanken (1982) demonstrated, though, that virtually any variables could serve as the factors in a welldefined strict factor model. One need only repackage an initial (finite) set of assets into an equivalent set of portfolios in order to fundamentally alter the associated factor space. ${ }^{2}$ Thus, the statistical assumptions underlying the APT cannot, by themselves, characterize the economically relevant components of returns.

Chamberlain and Rothschild (1983) shifted attention away from strict factor structures by proving that the APT holds, more generally, if returns conform to an approximate factor model. ${ }^{3}$ In this case, the disturbances need

\footnotetext{
* From the University of Rochester. The comments of an anonymous referee are gratefully acknowledged.

${ }^{1}$ The arbitrage assumption implicit in Ross's analysis was clarified by Huberman (1982). Shanken $(1985,1987)$ argues that the more recent equilibrium factor models, so-called "equilibrium-APT's," are subject to essentially the same empirical limitations as other preference-based equilibrium models.

${ }^{2}$ Shanken's argument has recently been extended by Gilles and Leroy (1991). Dybvig and Ross (1985) also discuss some theoretical implications for limiting economies.

${ }^{3}$ See related work by Stambaugh (1983) and Ingersoll (1984).
} 
not be uncorrelated, but the eigenvalues of the residual covariance matrix must remain bounded as the number of assets tends to infinity. While clarifying the underlying theory, the prescription for empirically specifying factors remains vague, since the approximate factor structure has precise meaning only for an infinite set of returns. Moreover, the conclusion of the APT is the same peculiar sort of approximation that permits arbitrarily large expected return deviations for any given finite set of assets. As Shanken (1982) has emphasized, the common interpretation of such arbitrage-based approximations as tantamount to equality is questionable and the relevance of the theory for actual investment practice, therefore, doubtful. ${ }^{4}$

A striking new result by Reisman (1992) reinforces these conclusions. Reisman shows that, as long as there exists an approximate factor structure for returns, almost any set of variables correlated with the factors can serve as the benchmark in an approximate APT expected return relation. The proxy variables need only satisfy the condition that the matrix of their slope coefficients in the multivariate regression on the factors be invertible. The variables might account for only a trivial fraction of the common variation in security returns and still an APT approximation of the sort first derived by Ross must hold.

If virtually any set of variables can serve as the benchmark in an approximate APT expected return relation, then it would appear essential to take into account the degree of approximation. However, Shanken (1982, Appendix A) notes that the bounds on APT approximations that have been derived in the arbitrage framework are mathematical tautologies, rather than economic restrictions, for finite sets of linearly independent assets. Therefore, there would appear to be no basis for the traditional view that the APT is a viable alternative to equilibrium asset pricing models like the Sharpe-Lintner CAPM or the intertemporal model of Merton (1973). Yet, a casual glance at current finance text books (and some of the academic literature) suggests that this view is still widely held.

In developing his theorem, Reisman draws upon the mathematical theory of Hilbert and Banach spaces, thereby limiting the potential audience for his work. In Section I, I provide a simple but nonetheless rigorous, derivation of the central conclusion of his analysis. In order to focus on the essential issues, with a minimum of algebraic and notational distraction, the singlefactor case is considered. Section II emphasizes a fundamental connection between the APT and recent tautologies derived in the literature on testing portfolio efficiency. The paper concludes on a positive note, in Section III, suggesting a new framework for empirical work that exploits these tautologies in the context of a large asset market.

\footnotetext{
${ }^{4}$ This has sometimes incorrectly been interpreted as an argument against the use of factor models in empirical work. Such models can be motivated outside the theoretical framework of the APT.
} 


\section{A Simple Proof of Reisman's Result}

Consider two infinite sequences of scalars, denoted $\mathrm{x}$ and $\mathrm{y}$. We say that $x$ is approximately equal to $y$, written $x \approx y$, if the infinite sum of squared components of the difference, $x-y$, is finite. One can easily show, appealing to the Cauchy-Schwarz inequality for finite vectors, that this relation is transitive; i.e., if $x \approx y$ and $y \approx z$ then $x \approx z$. When $x \approx c y$, for some scalar $c$, we say that $x$ is approximately proportional to $y$. This relation is symmetric in the sense that $x \approx c y$ and $c \neq 0$ clearly implies that $y \approx c^{-1} x$.

Assume that an infinite sequence of asset returns conforms to an approximate factor structure, as defined earlier. For simplicity, suppose there is a single factor $F$. While the APT can be derived under a variety of no-arbitrage conditions, we need only be concerned here with the conclusion; i.e., that the infinite sequence of expected returns is approximately equal to some linear function of the assets' factor betas. If we can show that the betas on $F$ are approximately proportional to the betas on a proxy $P$, it will follow, by transitivity, that expected returns are approximately equal to a linear function of the betas on $P$. We now proceed with the proof.

The factor representation for the first $N$ asset returns is written in vector form as

$$
R_{N}=a_{N}^{*}+b_{N} F+e_{N},
$$

where $\operatorname{cov}\left(e_{N}, F\right)=E\left(e_{N}\right)=0$. Let $C_{N}$ be the $N \times N$ covariance matrix for $e_{N}$ and let $u$ be an upper bound on the eigenvalues of $C_{N}$. By the approximate factor model assumption, $u$ can be taken to be independent of $N$. We then have

Lemma 1: Let $e_{p}$ be the residual from a regression of $P$ on $F$ and a constant, and let $d_{N}$ be the $N$-vector of covariances between $e_{p}$ and the components of $e_{N}$. Then

$$
d_{N}^{\prime} d_{N} \leq \operatorname{var}\left(e_{p}\right) u .
$$

Proof: The argument is similar to that in Shanken (1987). The vector of slope coefficients from the regression of $e_{p}$ on $e_{N}$ and a constant is $C_{N}^{-1} d_{N}$. The corresponding explained variation is $d_{N}^{\prime} C_{N}^{-1} d_{N}$, which must be less than $\operatorname{var}\left(e_{p}\right)$. The desired conclusion now follows from the fact that $1 / u$ is a lower bound on the eigenvalues of $C_{N}^{-1}$ and hence $d_{N}^{\prime} d_{N} / u \leq d_{N}^{\prime} C_{N}^{-1} d_{N}$.

Reisman's key insight is presented in

Lemma 2: If returns conform to an approximate factor structure then the betas on $P$ are approximately proportional to the betas on $F$. If , in addition, $P$ and $F$ are correlated, then the betas on $F$ are approximately proportional to the betas on $P$.

Proof: Assume, without loss of generality, that $\operatorname{var}(P)=1$. Then, using (1), the betas on $P$ equal $\operatorname{cov}\left(R_{N}, P\right)=b_{N} \operatorname{cov}(F, P)+\operatorname{cov}\left(e_{N}, P\right)$. The first conclusion, with $\operatorname{cov}(F, P)$ serving as the constant of proportionality, follows from (2) since $d_{N}=\operatorname{cov}\left(e_{N}, e_{p}\right)=\operatorname{cov}\left(e_{N}, P\right)$. The second conclusion follows by symmetry of the approximate proportionality relation $\operatorname{since} \operatorname{cov}(F, P) \neq 0$. 
The main result now follows.

Theorem 1: If returns conform to an approximate factor structure and there is no arbitrage, then expected returns are approximately linear in the betas on any proxy $P$ that is correlated with the factor $F$.

Proof: By the usual APT result, expected returns are approximately linear in the betas on $F$. By Lemma 2, these betas are approximately proportional to the betas on $P$. The conclusion now follows by the transitivity of the approximate equality relation.

We note the following technical points. First, the assumption of no arbitrage is not needed to derive Lemma 2. Also, in contrast to the development in Reisman (1992), we do not assume the existence of a riskless asset or require continuity of the asset pricing functional.

\section{Mean-Variance Tautologies and the APT}

As noted earlier, bounds on the APT approximation that have been derived in the arbitrage framework are mathematical tautologies for finite sets of linearly independent assets. Related tautologies have been obtained more recently in the portfolio efficiency literature (see Shanken (1987) and Gibbons, Ross, and Shanken (1989)), but the links between these literatures have gone largely unexplored. This section draws some important connections, providing additional perspective on the theoretical content of the APT. The final section considers the relevance of these connections for empirical work.

Assume, for simplicity, that the single factor, $F$, is a portfolio return. Consider the multivariate linear excess return regression

$$
R_{N}-R_{F} 1_{N}=a_{N}+b_{N}\left(F-R_{F}\right)+e_{N},
$$

where $R_{F}$ is the return on a riskless asset and $1_{N}$ is a vector of ones. The intercept vector, $a_{N}$, can be viewed as the vector of deviations from a linear risk-return relation with intercept, $R_{F}$, and factor price of risk, $E(F)-R_{F}$. As earlier, let $C_{N}$ be the residual covariance matrix.

Recall that a portfolio's Sharpe measure of performance is the ratio of its expected excess return to standard deviation of return. Gibbons, Ross, and Shanken (1989) derive the following mathematical tautology:

$$
a_{N}^{\prime} C_{N}^{-1} a_{N}=\theta_{t N}^{2}-\theta_{F}^{2},
$$

where $\theta_{F}$ is the Sharpe measure for $F$ and $\theta_{t N}$ is the Sharpe measure for the (efficient) tangency portfolio determined by the $N$ risky assets and the riskless return. ${ }^{5}$ In the usual case, if portfolios are plotted with expected return and standard deviation on the vertical and horizontal axes, respectively, $\theta_{t N}$ is the slope of the (linear) efficient frontier. When $F$ is itself the tangency portfolio return, (4) reduces to the familiar tautology, $a_{N}=0$. In

\footnotetext{
${ }^{5}$ See Shanken (1987) in the multifactor case.
} 
general, if $u$ is an upper bound on the eigenvalues of $C_{N}$ then, as in the proof of Lemma 1 ,

$$
a_{N}^{\prime} a_{N} \leq u\left(\theta_{t N}^{2}-\theta_{F}^{2}\right) .
$$

Now consider an infinite sequence of asset returns. If the sequence $\left\{\theta_{t N}\right\}$ is unbounded, the efficient frontier becomes vertical in the limit along some subsequence of the assets. Hence, it is possible, in the limit, to achieve various levels of expected return with no risk and, consequently, a positive return can be obtained with no risk and zero investment; i.e., there is an arbitrage opportunity. Therefore, if the eigenvalues of the residual covariance matrix remain bounded (the approximate factor model assumption) and there are no arbitrage opportunities, (5) implies that the infinite sum of squared deviations from the risk-return relation must be finite. Thus, all but finitely many deviations must be "small," the usual APT result. ${ }^{6}$

\section{Expected Return Deviations and Approximate Arbitrage}

Relations (4) and (5) cannot be viewed as testable hypotheses, since they are mathematical tautologies that always hold for finite $N$. Their value, from an empirical perspective, is that they permit the researcher to transform observed deviations from a risk-return relation into information about the efficient frontier and the relative performance of a given index. Gibbons, Ross, and Shanken (1987) make use of the equality (4) in developing an economic interpretation of their $F$ test for portfolio efficiency against a general alternative. Since the quadratic form in (4) involves the inverse of the residual covariance matrix, however, applications have been limited to relatively small numbers (often 10 or 20 ) of portfolios.

There is a long tradition in asset pricing empirical work of testing riskreturn relations against specific alternatives like residual variance or firm size (for example, Fama and MacBeth (1973) and Banz (1981)). Under appropriate assumptions one could, in such cases, obtain estimates of expected return deviations for a large number of individual securities. Given a value for $u$, the estimated deviations could then be used to obtain a lower bound on the difference of squared performance measures in (5). Of course, a number of statistical sampling issues arise, which will have to be considered in future applications.

As a hypothetical illustration of the suggested framework, suppose that $N=3000$ and the average squared deviation from a given risk-return relation is $(1 \%)^{2}$ per annum. Assume, further, that the residual covariance matrix is nearly diagonal, with maximum residual variance $(20 \%)^{2}$ and maximum eigenvalue slightly larger at 0.05 . By (5),

$$
3000(0.01)^{2}=0.30 \leq 0.05\left(\theta_{t}^{2}-\theta_{F^{\prime}}^{2}\right) .
$$

If the index has an expected excess return of $10 \%$ and standard deviation

\footnotetext{
${ }^{6}$ See Chamberlain and Rothschild (1983) for an analysis of arbitrage pricing and meanvariance mathematics in a Hilbert space setting.
} 
$20 \%, \theta_{F}=0.5$ and $\theta_{t} \geq 2.5$. Thus, in this example, one could obtain the expected excess return of $10 \%$ on an efficient portfolio with standard deviation $4 \% .^{7}$ Under the same assumptions, if we imagine that there are 3 million assets, then $\theta_{t} \geq 77.4$. In this case, something close to a "pure" arbitrage is possible (ignoring transaction costs), with $10 \%$ expected excess return and standard deviation less than $0.13 \%$.

Computations of this sort provide an informative metric for evaluating the deviations from an exact pricing relation. At the same time, practical content is given to the notion of "approximate arbitrage," by characterizing the investment opportunities that are available as a consequence of the observed expected return deviations. ${ }^{8}$ In contrast to this constructive approach, the traditional APT view treats even a single deviation as evidence of arbitrage, implicitly inferring the existence of infinitely many other comparable deviations in a hypothetical infinite sequence of assets. Far more will be learned, I believe, by examining the extent to which we can approximate an arbitrage with existing assets.

${ }^{7}$ Other tautologies in the literature could be exploited in a similar manner. A related computation appears in Ross (1976) but is interpreted quite differently.

${ }^{8}$ In conjunction with an assumption about the statistical relation between the factors and the benchmark in some equilibrium asset pricing model, one could obtain testable restrictions along the lines of Shanken (1987).

\section{REFERENCES}

Banz, R., 1981, The relations between returns and market values of common stocks, Journal of Financial Economics 9, 3-18.

Chamberlain, G. and M. Rothschild, 1983, Arbitrage, factor structure, and mean-variance analysis on large asset markets, Econometrica 51, 1281-1304.

Dybvig, P. and S. Ross, 1985, Yes, the APT is testable, Journal of Finance 40, 1173-1188.

Fama, E. F. and J. MacBeth, 1973, Risk, return, and equilibrium: Empirical tests, Journal of Political Economy 81, 607-636.

Gibbons, M., S. Ross, and J. Shanken, 1989, A test of the efficiency of a given portfolio, Econometrica 57, 1121-1152.

Gilles, G., and S. Leroy, 1991, On the arbitrage pricing theory, Economic Theory 1, 213-229.

Huberman, G., 1982, A simple approach to arbitrage pricing theory, Journal of Economic Theory $28,183-191$.

Ingersoll, J., 1984, Some results in the theory of arbitrage pricing, Journal of Finance 39, 1021-1039.

Merton, R. C., 1973, An intertemporal capital asset pricing model, Econometrica 41, 867-887.

Reisman, Haim, 1992, Reference variables, factor structure, and the approximate multibeta representation, Journal of Finance 47, 1303-1314.

Ross, S. A., 1976, The arbitrage theory of capital asset pricing, Journal of Economic Theory 13, 341-360.

Shanken, J., 1982, The arbitrage pricing theory: Is it testable?, Journal of Finance 37, 1129-1140. , 1985, Multi-beta CAPM or equilibrium-APT?: A reply, Journal of Finance 40, 1189-1196.

- 1987, Multivariate proxies and asset-pricing relations: Living with the Roll critique, Journal of Financial Economics 18, 91-110.

Stambaugh, R., 1983, Arbitrage pricing with information, Journal of Financial Economics 12, 357-369. 
http://www.jstor.org

\title{
LINKED CITATIONS
}

- Page 1 of 3 -

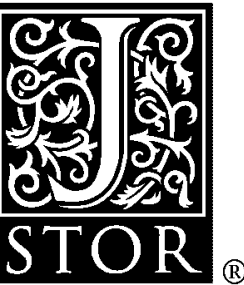

You have printed the following article:

\section{The Current State of the Arbitrage Pricing Theory}

Jay Shanken

The Journal of Finance, Vol. 47, No. 4. (Sep., 1992), pp. 1569-1574.

Stable URL:

http://links.jstor.org/sici?sici=0022-1082\%28199209\%2947\%3A4\%3C1569\%3ATCSOTA\%3E2.0.CO\%3B2-S

This article references the following linked citations. If you are trying to access articles from an off-campus location, you may be required to first logon via your library web site to access JSTOR. Please visit your library's website or contact a librarian to learn about options for remote access to JSTOR.

\section{[Footnotes]}

\author{
${ }^{1}$ Multi-Beta CAPM or Equilibrium-APT?: A Reply \\ Jay Shanken \\ The Journal of Finance, Vol. 40, No. 4. (Sep., 1985), pp. 1189-1196. \\ Stable URL: \\ http://links.jstor.org/sici?sici=0022-1082\%28198509\%2940\%3A4\%3C1189\%3AMCOEAR\%3E2.0.CO\%3B2-J
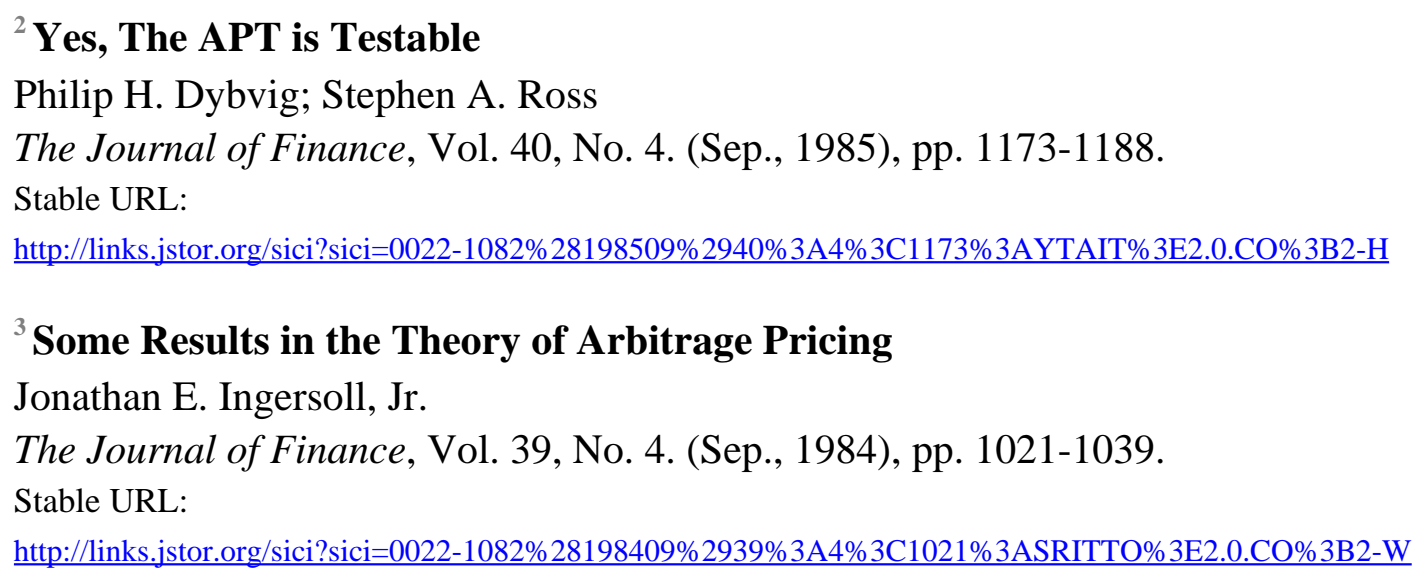

\footnotetext{
${ }^{6}$ Arbitrage, Factor Structure, and Mean-Variance Analysis on Large Asset Markets Gary Chamberlain; Michael Rothschild

Econometrica, Vol. 51, No. 5. (Sep., 1983), pp. 1281-1304.

Stable URL:

http://links.jstor.org/sici?sici=0012-9682\%28198309\%2951\%3A5\%3C1281\%3AAFSAMA\%3E2.0.CO\%3B2-B
}

NOTE: The reference numbering from the original has been maintained in this citation list. 
http://www.jstor.org

\section{LINKED CITATIONS}

- Page 2 of 3 -

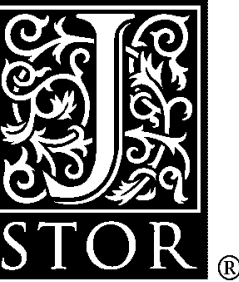

\section{References}

Arbitrage, Factor Structure, and Mean-Variance Analysis on Large Asset Markets Gary Chamberlain; Michael Rothschild

Econometrica, Vol. 51, No. 5. (Sep., 1983), pp. 1281-1304.

Stable URL:

http://links.jstor.org/sici?sici=0012-9682\%28198309\%2951\%3A5\%3C1281\%3AAFSAMA\%3E2.0.CO\%3B2-B

Yes, The APT is Testable

Philip H. Dybvig; Stephen A. Ross

The Journal of Finance, Vol. 40, No. 4. (Sep., 1985), pp. 1173-1188.

Stable URL:

http://links.jstor.org/sici?sici=0022-1082\%28198509\%2940\%3A4\%3C1173\%3AYTAIT\%3E2.0.CO\%3B2-H

Risk, Return, and Equilibrium: Empirical Tests

Eugene F. Fama; James D. MacBeth

The Journal of Political Economy, Vol. 81, No. 3. (May - Jun., 1973), pp. 607-636.

Stable URL:

http://links.jstor.org/sici?sici=0022-3808\%28197305\%2F06\%2981\%3A3\%3C607\%3ARRAEET\%3E2.0.CO\%3B2-J

\section{A Test of the Efficiency of a Given Portfolio}

Michael R. Gibbons; Stephen A. Ross; Jay Shanken

Econometrica, Vol. 57, No. 5. (Sep., 1989), pp. 1121-1152.

Stable URL:

http://links.jstor.org/sici?sici=0012-9682\%28198909\%2957\%3A5\%3C1121\%3AATOTEO\%3E2.0.CO\%3B2-P

\section{Some Results in the Theory of Arbitrage Pricing}

Jonathan E. Ingersoll, Jr.

The Journal of Finance, Vol. 39, No. 4. (Sep., 1984), pp. 1021-1039.

Stable URL:

http://links.jstor.org/sici?sici=0022-1082\%28198409\%2939\%3A4\%3C1021\%3ASRITTO\%3E2.0.CO\%3B2-W

NOTE: The reference numbering from the original has been maintained in this citation list. 
http://www.jstor.org

\section{LINKED CITATIONS \\ - Page 3 of 3 -}

\section{An Intertemporal Capital Asset Pricing Model}

Robert C. Merton

Econometrica, Vol. 41, No. 5. (Sep., 1973), pp. 867-887.

Stable URL:

http://links.jstor.org/sici?sici=0012-9682\%28197309\%2941\%3A5\%3C867\%3AAICAPM\%3E2.0.CO\%3B2-E

Reference Variables, Factor Structure, and the Approximate Multibeta Representation Haim Reisman

The Journal of Finance, Vol. 47, No. 4. (Sep., 1992), pp. 1303-1314.

Stable URL:

http://links.jstor.org/sici?sici=0022-1082\%28199209\%2947\%3A4\%3C1303\%3ARVFSAT\%3E2.0.CO\%3B2-\%23

The Arbitrage Pricing Theory: Is it Testable?

Jay Shanken

The Journal of Finance, Vol. 37, No. 5. (Dec., 1982), pp. 1129-1140.

Stable URL:

http://links.jstor.org/sici?sici=0022-1082\%28198212\%2937\%3A5\%3C1129\%3ATAPTII\%3E2.0.CO\%3B2-U

\section{Multi-Beta CAPM or Equilibrium-APT?: A Reply}

Jay Shanken

The Journal of Finance, Vol. 40, No. 4. (Sep., 1985), pp. 1189-1196.

Stable URL:

http://links.jstor.org/sici?sici=0022-1082\%28198509\%2940\%3A4\%3C1189\%3AMCOEAR\%3E2.0.CO\%3B2-J

NOTE: The reference numbering from the original has been maintained in this citation list. 